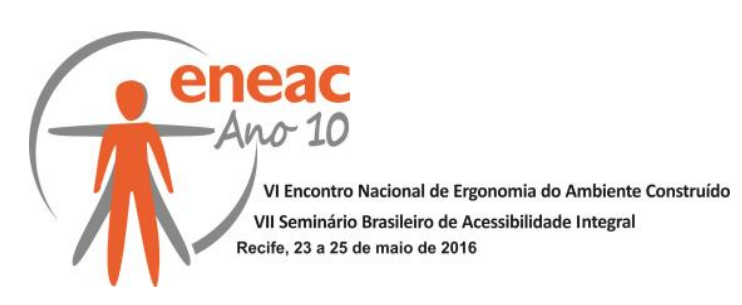

\title{
ESTUDO DE AMBIÊNCIA NO AMBIENTE CONSTRUÍDO SOB O OLHAR DO CUIDADOR DE IDOSO
}

\author{
FREITAS, Irai Borges de (1); \\ FREITAS, Katia Butter Leão (2); \\ AZEVEDO, Paulo Roberto de (3); \\ LOPES, Sarita de Oliveira Ferreira (4) \\ (1) Fundação Oswaldo Cruz, Mestre em Desenvolvimento Local \\ e-mail: irai.borges@gmail.com \\ (2) Fundação Oswaldo Cruz, Mestre em Ciências \\ e-mail: katia.butter@gmail.com \\ (3) Fundação Oswaldo Cruz, Especialista em Ergonomia e Usabilidade \\ e-mail: paullor@oi.com.br \\ (4) Fundação Oswaldo Cruz, Mestre em Educação Profissional em Saúde \\ e-mail: saritaofl@gmail.com
}

\begin{abstract}
RESUMO
Este estudo tem como tema a ambiência. Com abordagem qualitativa, os alunos do Curso de Atualização Profissional no Cuidado ao Idoso Dependente, da Escola Politécnica de Saúde Joaquim Venâncio (EPSJV/FIOCRUZ), elaboraram na sala do Núcleo de ErgoAmbiência manchas de cinco ambientes distintos, inserindo nesses os elementos humanizadores da cartilha Ambiência, do Ministério da Saúde. Conclui-se que a ambiência é uma ferramenta potencializadora de um espaço construído acolhedor, resolutivo, seguro e saudável e que pode favorecer a autonomia do idoso.
\end{abstract}

Palavras chave: Ambiência; Cuidador de Idoso; Idoso; Ergonomia.

\begin{abstract}
This study has as its theme the ambience. With a qualitative approach, the Professional Development Course Students in Caring for Elderly Dependent, the Polytechnic School of Health Joaquim Venâncio ( EPSJV / FIOCRUZ ), developed in the Core room ErgoAmbiência five distinct environments, spots by entering these the humanizing elements of ambience primer, the Ministry of Health. It is concluded that the ambience is a potentiating tool a built cozy, resolute, healthy and can promote the autonomy of the elderly.
\end{abstract}

Keywords: Ambience; Caregiver for elderly;. Elderly ; Ergonomic. 


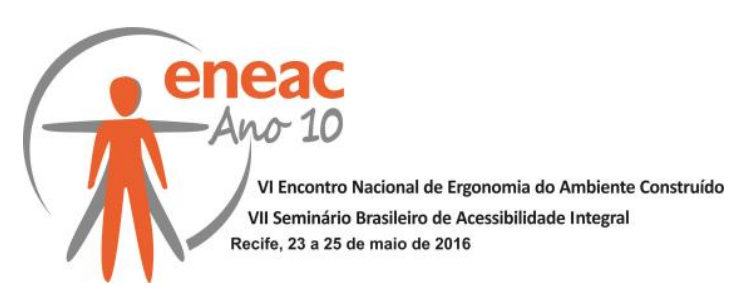

\section{INTRODUÇÃO}

Este estudo apresenta os resultados de demanda da coordenação do Curso de Atualização Profissional no Cuidado ao Idoso Dependente, do Laboratório (LABORAT), em parceria com - Laboratório de Educação Profissional em Manutenção de Equipamentos de Saúde (LABMAN), ambos da Escola Politécnica de Saúde Joaquim Venâncio (EPSJV), da Fundação Oswaldo Cruz (FIOCRUZ), instituição pública de saúde do Rio de Janeiro.

Tem como objetivo geral, possibilitar uma reflexão sobre a relação existente entre o ambiente construído, a qualidade de vida, a saúde e a segurança do idoso. Também apresenta como objetivos específicos: trazer para os trabalhadores e cuidadores a temática de ambiência com uma abordagem analítica, crítica e transformadora do ambiente construído do idoso; aplicar os conhecimentos construídos em sala do Núcleo de ErgoAmbiência, num esboço de mancha que expresse um ambiente construído humanizado, acolhedor e resolutivo para o idoso.

Ao longo dos anos o perfil da população brasileira modificou, apresentando mais idosos que muitas vezes necessitam de alguém que cuide deles. Esse cuidado, não se limita a assistência médica, com profissionais capacitados, equipamentos, tecnologias e medicamentos. Envolve também o ambiente que os idosos se encontram, pois, "O espaço físico habitado tem o poder de relacionar todas as coisas e pessoas, podendo deprimir, incentivar, cuidar ou até mesmo colocar em risco a pessoa que o utiliza". (BEZERRA; BARROS, 2014).

Diante do exposto, observa-se existir um aumento da ocupação de cuidador de idoso, que não é uma profissão regulamentada por Lei, mas é uma ocupação existente no mercado de trabalho e reconhecida pela Classificação Brasileira de Ocupações - CBO, do Ministério do Trabalho e Emprego (BRASIL, 2014). Este pode ser um familiar ou uma pessoa designada por essa, podendo atuar como mediador entre a ambiência e a qualidade de vida do idoso.

O tema ambiência remete-se a influência do ambiente construído sobre o comportamento humano. Assim, o Ministério da Saúde (BRASIL, 2010), no ano de 2004, disponibilizou na versão digital uma cartilha intitulada Ambiência, compreendendo que "Ambiência na saúde refere-se ao tratamento dado ao espaço físico entendido como espaço social, profissional e de relações interpessoais que deve proporcionar atenção acolhedora, resolutiva e humana". Apresenta dez elementos humanizadores (morfologia; luz; cheiro; som; sinestesia; arte; cor; tratamento das áreas externas; privacidade e individualidade; e confortabilidade), e afirma que o tratamento do ambiente pode facilitar a promoção e a recuperação da saúde dos usuários; sendo a ambiência, portanto, potenciadora das condições biopsicossociais dos sujeitos.

Ao compreendermos os elementos humanizadores podemos observar a existência de uma relação com a Ergonomia no ambiente construído, pois ambos buscam a confortabilidade e segurança do ambiente e dos usuários, além de se reportarem ao conforto lumínico, acústico e térmico.

A relevância deste estudo se justifica, pois, a saúde compreende uma diversidade de aspectos, subjetivos e complexos, que necessita de conhecimentos com abordagens diversas, e 0 ambiente em que se vive pode representar um papel fundamental para alcançá-la ou não.

Ao se reportar ao idoso, é necessário que o ambiente proporcione saúde, segurança e acolhimento e que favoreça a integração, considerando as dificuldades, limitações e necessidades, podendo dessa forma contribuir para a qualidade de vida. A importância do ambiente em que vivem os idosos, com direito a moradia digna, limpos, adequados as suas necessidades físicas e providos de alimentação, é reafirmado pelo Estatuto do Idoso (BRASIL, 2003). 


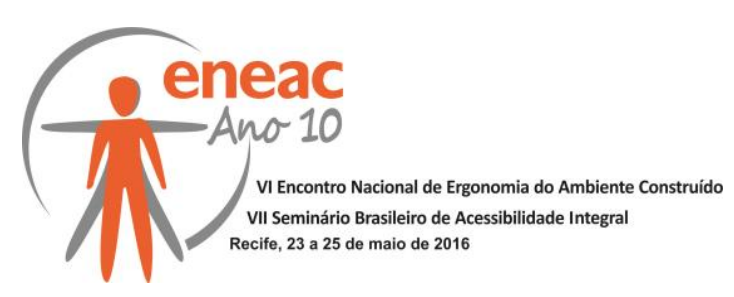

Sendo assim, capacitar Cuidadores de idosos, com enfoque na ambiência dos ambientes construídos, é poder contribuir com a saúde e segurança dos idosos e para o fortalecimento de uma política educacional fundamentando os princípios do Sistema Único de Saúde SUS.

Vale ressaltar que o trabalho é indissociável à saúde e o processo de trabalho pode ser visto como fator determinante de saúde e doença (FREITAS; LOPES, 2008), portanto, a ambiência poderá também favorecer as relações existentes entre o Cuidador, o idoso e demais pessoas existentes nos espaços.

\section{A AMBIÊNCIA E OS ELEMENTOS HUMANIZADORES}

Paiva e Santos (2012) compreendem que "o ambiente é fundamental por ser responsável pelo atendimento de necessidades funcionais (aspectos físico-cognitivos) e formais (aspectos psicológicos) ", portanto o espaço construído pode ter um papel relevante para o envelhecimento com qualidade.

Reafirmando o conceito de ambiência utilizado pelo Ministério da Saúde, Bestetti (2014) afirma que "A história que vamos compondo junto aos grupos familiar e social ao qual pertencemos suscitará as emoções, positivas ou negativas, que podem interferir no conforto e na relação que estabelecemos com o ambiente construído".

A cartilha 'Ambiência' apresenta dez elementos humanizadores potencializadores das sensações e percepções dos indivíduos: morfologia, luz, cheiro, som, sinestesia, arte, cor, tratamento das áreas externas, privacidade e individualidade e a confortabilidade.

A morfologia se refere a formas, dimensões e volumes que configuram os espaços, que permitem diversas e diferentes compreensões do ambiente. De acordo com Rybezynski, (1999), "Os móveis internos da casa surgiram com os móveis internos da mente".

A luz pode ser natural e artificial. A luz natural deve ser utilizada o máximo possível, além de ser uma ação sustentável também permite por meio dos raios solares a ação para purificação dos ambientes (LENGEN, 2008 apud FREITAS, 2010) e dificultando a proliferação de micro-organismos como ácaro, fungos, vírus e bactérias, que podem prejudicar a saúde dos usuários desses espaços. Já a luz artificial deve complementar a natural sempre que se fizer necessário.

O cheiro pode ter origem de diferentes fontes, como de elementos químicos e do metabolismo humano e pode ser agradável ou desagradável. No ambiente de moradia, geralmente é proveniente de fossas, cocção, banheiros, dentre outros. Com o avançar da idade geralmente os idosos apresentam perda de visão e o cheiro os possibilitam a identificação de objetos, alimentos e ambientes.

O som é o resultado audível de uma vibração e está associado a subjetividade humana. Pode ser agradável ou se tornar um ruído, ou seja, um som desagradável que deve ser controlado. Os ruídos podem ser oriundos de fontes externas ou internas das edificações. (FREITAS, 2014). Da mesma forma que o ruído possibilita o desconforto acústico o silêncio pode provocar sensações de insegurança e de medo (BESTETTI, 2014).

Papanek (1995) estima que haverá um maior quantitativo de idosos com problemas de surdez em consequência de existir um número considerável de jovens com perda auditiva devido ouvirem músicas com volume elevado. 


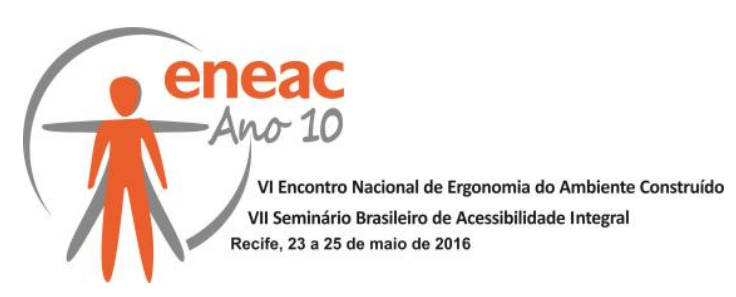

A sinestesia está relacionada com a percepção do espaço através dos movimentos, superfícies e texturas. Para Papanek (1995) os sentidos humanos possibilitam criar experiências singulares. O sentido da visão permite criar pré-conceitos e conclusões de acordo com o efeito que causam aos olhos. Já o olfato e a audição potencializam a memorização de experiências e lugares vividos. No que se refere ao tato, este possibilita ao indivíduo sentir um objeto, superfície e pessoa por meio do toque dos pés, mãos ou qualquer outra parte do corpo, podendo-se associar a segurança, prazer, temperatura. $E$ em fim, a audição, que nos remete a música e é potencializadora de sensações positivas ou negativas.

A arte, é um dos elementos humanizadores que segundo a cartilha 'Ambiência' (BRASIL, 2010) atua "como meio de inter-relação e expressão das sensações humanas". No ambiente construído pode ser expressada por meio de quadros decorativos, objetos confeccionados ou não pelo próprio idoso que podem ser expressão da cultura e história de vida dos usuários dos ambientes construídos, por meio das cores, linhas e sentimentos.

As cores potencializam transformações dos ambientes e "podem alterar a comunicação, as atitudes e a aparência das pessoas presentes, pois todos nós temos reações às cores." (BOCCANERA; BOCCANERA; BARBOSA, 2006).

Cores frias e tons pastéis, são relaxantes e podem ser acrescentadas de alguns detalhes de cores quentes, como alisares, portas, bate-macas para compor ambientes acolhedores e seguros. Já o uso de cores quentes quebrando a monocromia pode evitar a depressão trazendo estímulos. Costi (2002) compreende que as cores podem até sugerir funções servindo para "acentuar a forma, as divisões e outros elementos arquitetônicos". Os ambientes monocromáticos podem ser monótonos e os policromáticos podem ser confusos e estressantes, mas quando bem planejados podem compor um conjunto harmonioso (FREITAS, 2014).

O tratamento das áreas externas se reporta as áreas que muitas vezes constituem a porta de entrada de uma edificação, podendo ser lugares de espera ou de descanso de trabalhadores. Varandas e corredores externos que possuem plantas podem proporcionar 0 contato do idoso com a natureza, além de poderem ser utilizados para banho de Sol e lazer. Os jardins e áreas com bancos podem se tornar lugares de repouso e relaxamento. Entretanto, não se simplifica em uma montagem de jardim, pois devem ser expressão da cultura local e incorporar as formações naturais sem imitá-las (FREITAS, 2014).

A temperatura, radiação e o movimento do ar são os elementos climáticos que se destacam na percepção térmica, fisiológica e comportamental do ser humano. Assim, o paisagismo vegetal pode ser utilizado para o conforto térmico (BUSTOS ROMERO, 2000).

A privacidade e individualidade devem ser consideradas, buscando uma atenção da Arquitetura não só naquilo que os olhos do ser humano conseguem ver, mas contemplando as subjetividades dos sujeitos. Quando acolhidas pela Arquitetura podem construir ambientes sustentáveis que beneficiam os usuários. Um espaço reservado para guardar os objetos individuais, pode representar valores que expressam as suas particularidades (FREITAS, 2014).

A noção de conforto se modificou quando a casa deixou de ser meramente um abrigo com a função de proteção contra a natureza e invasores. Passou então a ser expressão de ambiente que comporta a família, que necessita também de privacidade e individualidade (SUDSILOWSKY, 2002). 


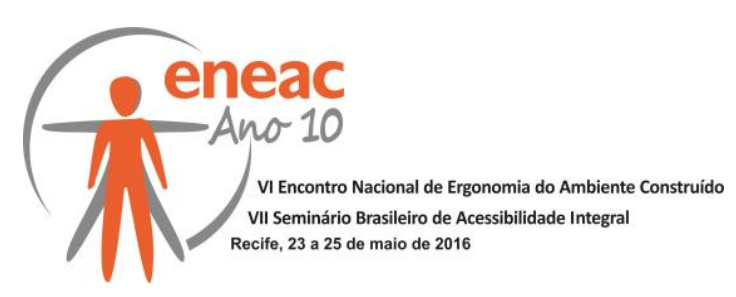

A confortabilidade na cartilha 'Ambiência' (BRASIL, 2010) faz relação com a acessibilidade, tendo um ambiente adaptado para pessoas portadoras de deficiência. $E$ quando nos referimos a idosos não podemos esquecer de que muitos são portadores de limitações físicas. Portanto, a inexistência de barreiras arquitetônicas no interior e aos redores da edificação contribui na mobilidade dos idosos e pode evitar incidentes e acidentes.

De acordo com Bins Ely (2003, apud VILLAROUCO e ANDRETO, 2008), o ambiente possui papel relevante pois suas características podem facilitar ou dificultar as atividades exercidas nele.

\section{A ERGONOMIA NO AMBIENTE CONSTRUÍDO DO IDOSO}

A Ergonomia compreende as relações existentes entre os elementos do ambiente construído e a análise de atividades físicas e cognitivas dos usuários. Esse ambiente ergonômico, de acordo com Bezerra e Barros (2014) "tem o poder de relacionar todas as coisas e pessoas, podendo deprimir, incentivar, cuidar ou até mesmo colocar em risco a pessoa que o utiliza". Parte do conhecimento do indivíduo para fazer o projeto relacionado ao trabalho, buscando ajustá-lo às capacidades e limitações dele.

Ao se reportar ao idoso, o avançar da idade contribui com que ocorram limitações físicas e nesse sentido, torna-se relevante pensar na moradia, como um ambiente acolhedor, seguro e prazeroso. Ou seja, o espaço deve acompanhar as mudanças que ao longo dos anos ocorrem no corpo humano em função do envelhecimento, possibilitando aos idosos, mecanismos que garantam uma maior socialização, independência, acessibilidade aos espaços e mobiliários.

Nesse sentido destaca-se a Antropometria que irá buscar por meios singulares possibilitar o alcance e acessibilidade do idoso, não se prendendo a padrões existentes, mas ajustando as inadequações presentes no ambiente às características corporais e à antropometria do idoso.

Quaresma e Moraes (2000) compreendem que a antropometria é uma ferramenta básica para os ergodesigners no desenvolvimento de projetos, pois abrange aspectos de alcances, tamanhos, proporções, mobilidades, forças, dentre outros relacionados aos indivíduos. Portanto, pode possibilitar posturas mais adequadas e movimentos mais seguros.

Os ambientes construídos podem apresentar diversos fatores de riscos ergonômicos, tais como: degraus estreitos, superfícies de escada escorregadias, tapetes soltos, iluminação insuficiente, pisos escorregadios, calçadas quebradas ou irregulares, espaços estreitos que contribuem para a ocorrência de incidentes como quedas e acidentes principalmente dos idosos.

Modificações no ambiente de moradia por meio da ambiência e da Ergonomia incluem a instalação de artefatos protetores em escadas, como corrimãos, barras de apoio e superfícies não escorregadias no banheiro, iluminação adequada e barras de apoio nos demais ambientes, que possibilitam otimizar o trabalho do Cuidador de idoso e também reduzir os riscos para todos os usuários do ambiente.

\section{O IDOSO E O CUIDADOR DE IDOSO}

O cuidado requer o atendimento integral ao ser humano de forma a proporcionar ao mesmo bem-estar biopsicossocial. De acordo com Waldow (2007), o "Cuidado consiste de esforços transpessoais de ser humano para ser humano no sentido de proteger, promover e preservar a humanidade, ajudando pessoas a encontrarem significado na doença, sofrimento e dor, bem como na existência. É ainda ajudar a outra pessoa a obter 


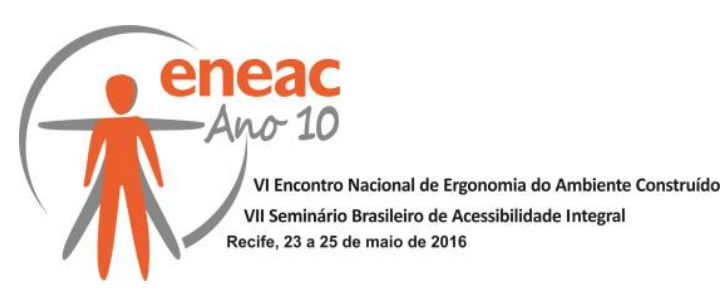

autoconhecimento, controle e autocura, quando um sentimento de harmonia interna é restaurado, independentemente de circunstancias externas".

Para Mendes (1998 apud BARBOSA, 2010) o cuidar compreende um conjunto de atividades, tais como "[...] administrar remédios, assegurar uma dieta alimentar, efetuar a higiene pessoal, pentear o cabelo, escovar os dentes, cortar as unhas, dar banho, fazer a toalete, vestir, despir, locomover de um lugar para o outro (quarto/sala, quarto/banheiro), subir escada, sentar, levantar, deitar e realizar exercícios motores complementares à fisioterapia".

Nesse sentido, Martinez (2009) compreende que o papel do cuidador não se limita ao campo da saúde, mas compreende também o campo social e humano, por isso utiliza a terminologia cuidador social. Segundo a autora, "[...] o cuidador social é aquela pessoa que tem compreensão da realidade e consequências sociais do envelhecer, em especial, que está preparada para auxiliar as pessoas em suas necessidades cotidianas enquanto sujeito envelhecido, e que a partir daí se coloca disponível para respeitar o idoso em sua condição $e$ atender com mais qualidade à demanda do cuidado, qualquer que seja ela, e que se identifique com o ato - humano e social - de cuidar".

O aumento da longevidade no país e a inserção da mulher no mercado de trabalho são fatores de contribuíram com que a ocupação de cuidador crescesse (BARBOSA, 2010). Consequentemente, o tempo dos familiares para cuidar de parentes idosos fragilizados reduziu, atraindo cada vez mais cuidadores domiciliares.

Assim, o cuidador domiciliar tornou-se mais presente no lar do idoso e "poderá se transformar no melhor meio de comunicação entre o idoso, a família e/ou a equipe de saúde”. (MARTINEZ; MARQUES; SILVA, 2009).

\section{METODOLOGIA}

A pesquisa apresenta uma abordagem qualitativa, ou seja, busca a compreensão de subjetividades (MINAYO, 2004) de alunos com experiência ou não no cuidado com idosos.

Comporam a aula, quatro docentes que em sala distribuíram um formulário a cada aluno para que pudessem descrever quais os aspectos necessários para a qualidade de vida dos idosos; se existe alguma relação entre qualidade de vida e felicidade e por quê. A seguir, os alunos foram encaminhados para a sala do Núcleo de ErgoAmbiência para estimular a percepção e a sensação deles sobre os elementos humanizadores ali utilizados.

O passo seguinte foi dividir em 5 grupos os alunos e realizar a distribuição da cartilha Ambiência para leitura e apoio na construção do desenho das manchas dos ambientes do espaço construído: cozinha, banheiro, sala, quarto e área externa. De acordo que se ministrava os conhecimentos sobre cada elemento humanizador, apresentados pela cartilha Ambiência, os alunos os inseriam no desenho das manchas.

Ao término do desenho das manchas, o representante de cada grupo apresentou para todos os componentes relacionados a cada elemento humanizador. O docente de Ergodesign elaborou na lousa, um esboço reunindo todos os ambientes para que todos tivessem o conhecimento compartilhado do espaço construído ideal ao idoso.

Em seguida, distribuiu-se um texto relacionado ao tema para que o aluno realizasse um resumo de entendimento para ser entregue na próxima aula do Curso, e por fim, houve apresentação de vídeos sobre saúde e qualidade de vida do idoso.

\section{RESULTADOS}

Do total de seis manchas que foram elaboradas, uma apresenta a junção de todos os ambientes desenhados pelos alunos. Dentre as cinco elaboradas pelos alunos, foram 


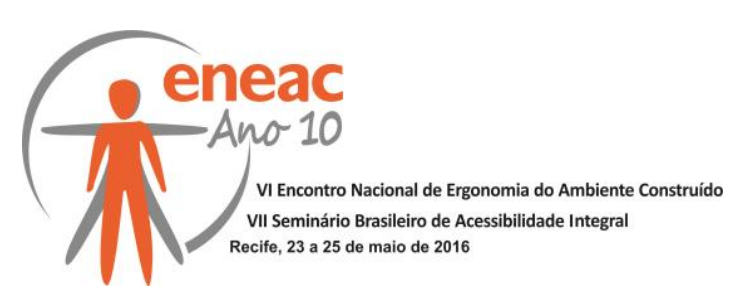

apontados os seguintes aspectos da ambiência necessários no espaço construído do idoso: cores diferentes nos pisos e nas paredes, para evitar quedas e facilitar a percepção; luzes de emergência; sensores de presença; som nos ambientes; ralos vedados para evitar cheiros desagradáveis e entrada de insetos indesejados; paredes com diferentes texturas para facilitar a identificação dos ambientes; portas com acessibilidade para cadeiras de roda e andador, proporcionando maior autonomia; maçanetas de alavanca. Janelas amplas para melhor arejar o ambiente; cadeiras com braços para maior segurança e facilitar o levantar e o sentar; quadros decorativos nas paredes e porta-retratos, expressando a história de vida e cultura; móveis sem quinas e fixos no chão, evitando possíveis acidentes; cortinas e/ou persianas, para favorecer o conforto lumínico e térmico; lixeiras com tampa; altura de armários e pia adaptada ao idoso para que tenha liberdade em realizar algumas tarefas. Jardineiras nas janelas para plantar temperos, aromatizando de maneira sustentável o ambiente interno; pisos antiderrapantes, para evitar escorregões e quedas; barras de apoio no banheiro, facilitando o uso do ambiente e promovendo a privacidade; vegetação externa para tornar o local bonito e proporcionar o contato com a natureza; piso podotátil na área externa para direcionar; ausência de barreiras e poltrona no quarto e na sala para maior conforto.

Figura 1: Mancha da sala de estar

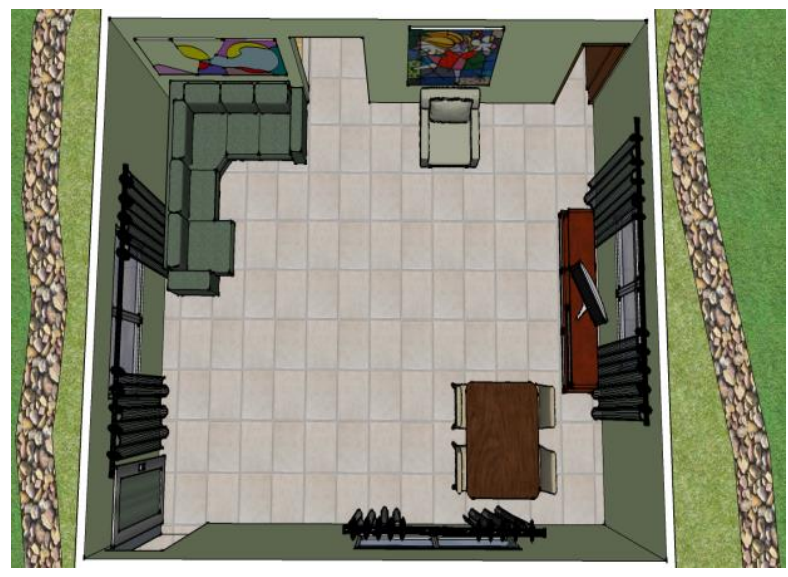

Fonte: Dos autores

Figuras 2: Mancha da cozinha

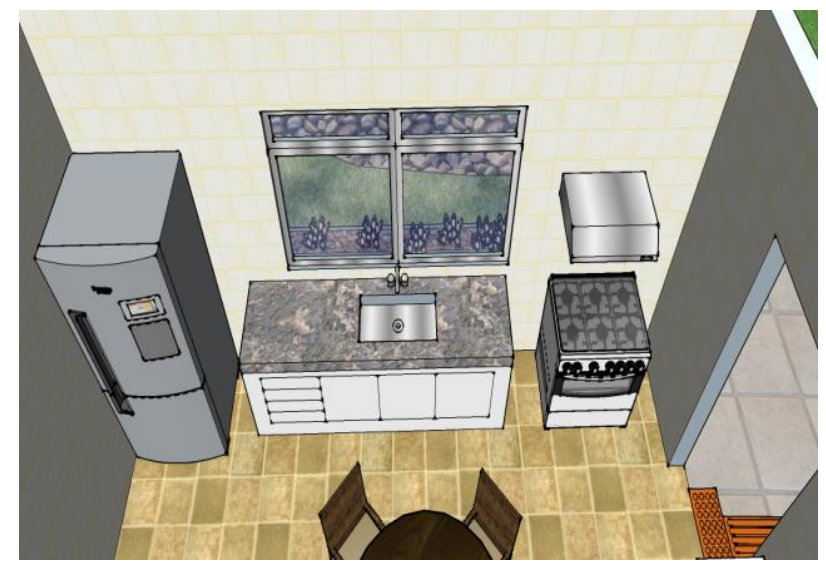

Fonte: Dos autores.

Figuras 3: Mancha do banheiro. 

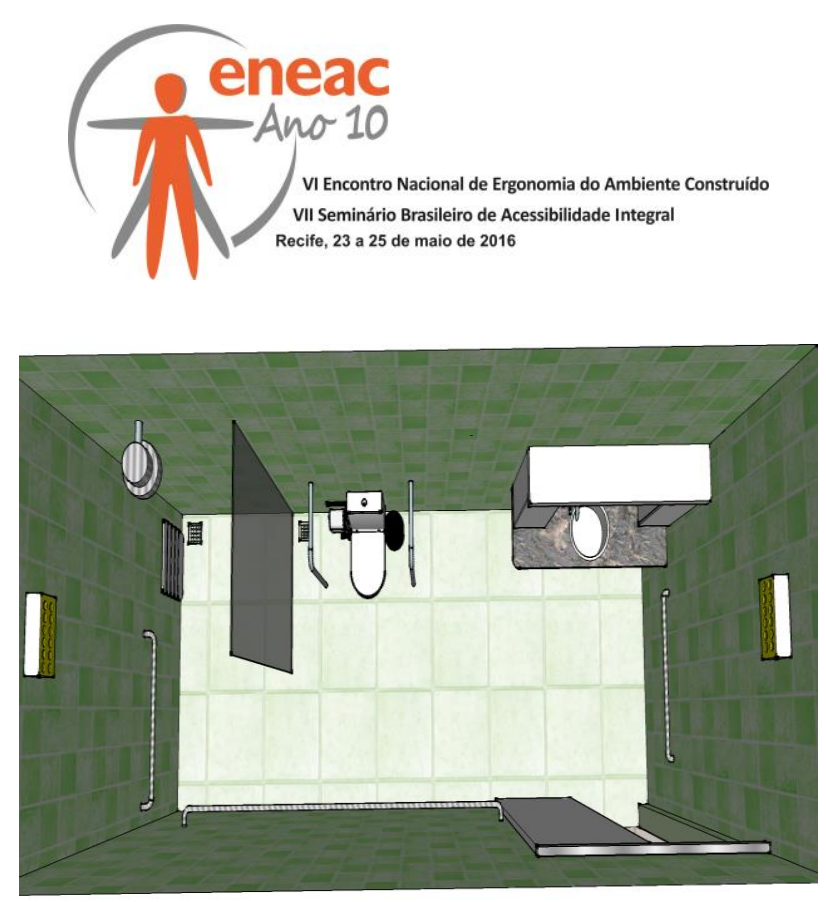

Fonte: Dos autores.

Figuras 4: Mancha do quarto de dormir.

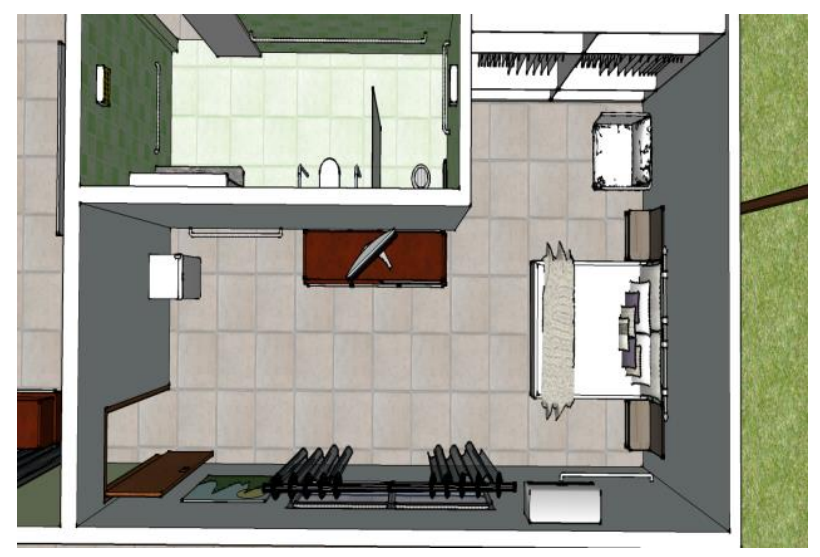

Fonte: Dos autores.

Figuras 5: Mancha da área externa.

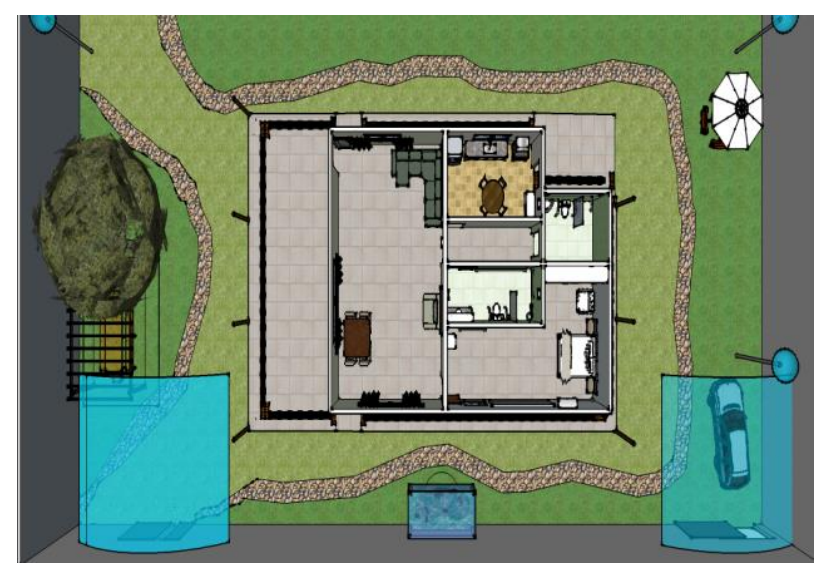

Fonte: Dos autores. 


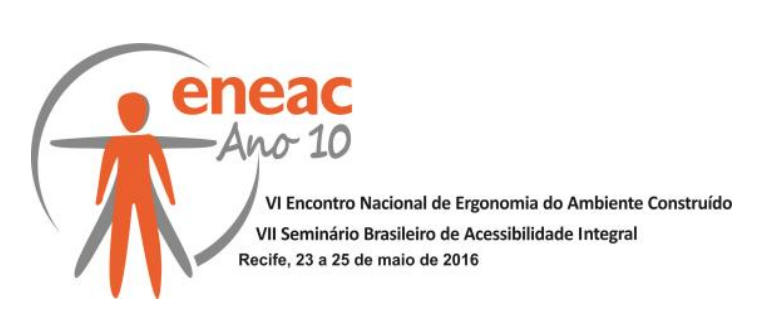

Figura 6: Mancha do ambiente construído.

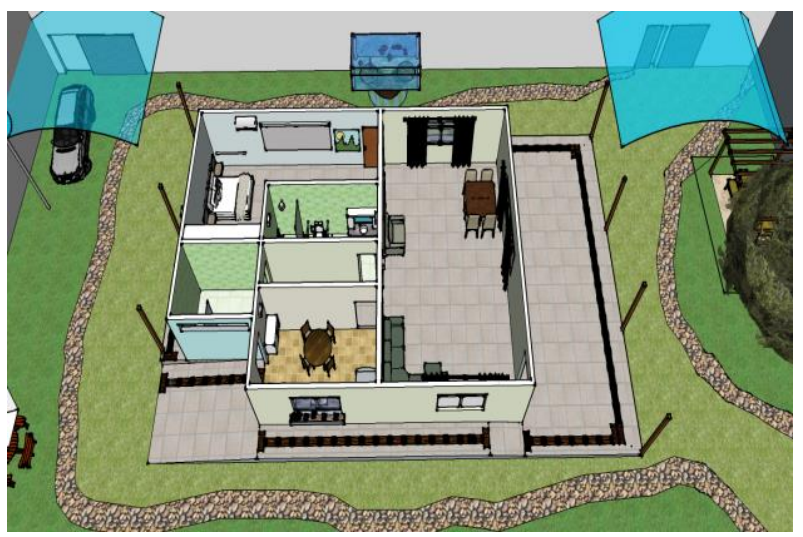

Fonte: Dos autores.

\section{CONSIDERAÇÕES FINAIS}

A ambiência compreende um conjunto de recursos que podem colaborar na saúde, na segurança e na autonomia dos idosos por meio dos espaços acolhedores e resolutivos. $O$ ambiente construído pode facilitar ou dificultar as ações dos usuários.

A Ergonomia pode tornar os espaços mais humanizados e funcionais, considerando as capacidades e limitações dos usuários, distanciando padrões existentes e contemplando as subjetividades dos mesmos.

Capacitar os Cuidadores de idosos com o tema ambiência, é possibilitar que eles atuem de maneira relevante na relação do idoso com a família e com o ambiente. É dar meios para que os cuidadores possam fazer desta uma ferramenta potencializadora nos cuidados com o idoso.

\section{REFERÊNCIAS BIBLIOGRÁFICAS}

BRASIL. Ministério da Saúde. Secretaria de Atenção à Saúde. Núcleo Técnico da Política Nacional de Humanização. Ambiência. $2^{\underline{a}}$ ed. Brasília: Editora do Ministério da Saúde, 2010 (Série B. Textos Básicos de Saúde).

Estatuto do idoso. Lei no 10741. Brasília: Ministério da Saúde, 2003.

- Ministério do Trabalho e Emprego. Classificação Brasileira de Ocupações. Disponível em: < www.mtecbo.gov.br/>. Acesso em: 02 jan. 2015.

BARBOSA, Elizabeth Sério; ARAUJO, Eliete de Pinho. Edifícios e habitações sociais humanizados para idosos. Universitas: Arquitetura e Comunicação Social, v. 11, n. 2, p. 716, jul./dez. 2014.

BESTETTI, Maria Luisa Trindade. Ambiência: espaço físico e comportamento. In: Revista Brasileira de Geriatria e Gerontologia. Universidade do Estado do Rio de Janeiro, Universidade Aberta da Terceira Idade, Centro de Referência e Documentação sobre Envelhecimento. Rio de Janeiro, v. 17, n.3, jul/set 2014.

BEZERRA, Mariana; BARROS, Bruno. Idosos versus ambiente reduzidos: discussões e projeto para uma cozinha de dimensões mínimas. In: Um novo olhar para o projeto, a ergonomia no ambiente construído. Mont'Alvão e Vilarouco (org.). Recife, v. 2, p. 67-85, 2014. 


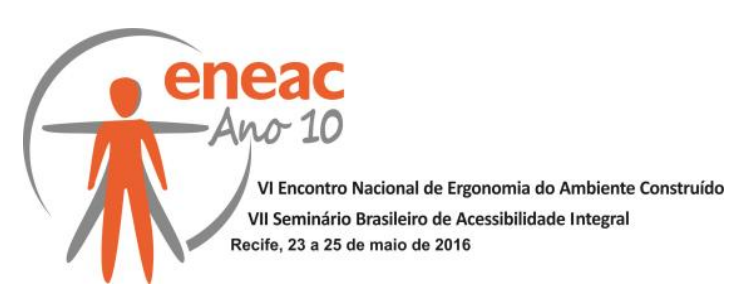

BOCCANERA, Nélio Barbosa; BOCCANERA, Silvia Fernandes Borges; BARBOSA, Maria Alves. As cores no de terapia intensiva: percepções de pacientes e profissionais. In: Revista da Escola de Enfermagem da USP. São Paulo, v. 40, n.3, p. 343-349, 2006.

BUSTOS ROMERO, Marta Adriana. Reabilitação Ambiental Sustentável Arquitetônica e Urbanística.Marta Adriano Bustos Romero, org. com a colab. de Daniel Dresch, Joe Rodrigues. Brasilia: FAU/UnB,2009.

COSTI, Marilice Costa, A influência da luz e da cor em salas de espera e corredores hospitalares. Porto Alegre: EDIPUCRS, 2002.256p.il.

FREITAS, Irai Borges de; LOPES, Sarita Oliveira Ferreira. Perspectiva do uso da ambiência no contexto do SUS. Trabalho de monografia do Curso de Pós-Graduação em Saúde do Trabalhador e Ecologia Humana, Cesteh/Ensp/Fiocruz, 2008.

FREITAS, Irai Borges de. Humanização em ambientes interiores de saúde: reflexões e contribuições a partir de princípios ergonômicos. Universidade Estácio de Sá. Especialização no curso de Arquitetura de interiores. Rio de Janeiro, 2010.

FREITAS, Irai Borges de. Proposta de Gestão Sustentável para os Estabelecimentos Assistenciais de Saúde a partir da Metodologia de Roda. Dissertação de Mestrado. Centro Universitário Augusto Motta. Pró-Reitorias de Ensino e de Pesquisa e Extensão. Programa de Pós-Graduação em Desenvolvimento Local - PPGDL. Mestrado Profissional Multidisciplinar em Desenvolvimento Local, 2014.

MARTINEZ, Terezinha Monteiro; MARQUES, Emilly Pereira; SILVA, Evelyn de Melo. Envelhecimento e cuidado social: um debate necessário. In: Envelhecimento e vida saudável. Edmundo de Drummond Alves Junior (Org.). Rio de Janeiro: Apicuri, 2009.

MINAYO, Maria Cecília de Souza. O desafio do conhecimento: pesquisa qualitativa em saúde. 8ª edição. São Paulo: Hucitec, 2004.

PAIVA, Marie Monique Bruere; SANTOS, Vilma Maria Villarouco. Ergonomia no ambiente construído em moradia coletiva para idosos: estudo de caso em Portugal. In: Revista Brasileira de Ergonomia, v. 7, n. 3, 2012. Disponível em: <http://www.abergo.org.br/revista/index.php/ae/article/view/169/169 >. Acesso em: 01 de fev. 2016.

PAPANEK, Victor. Arquitectura e design - Ecologia e Ética. Portugal: Edições 70, 1995.

QUARESMA, M.; MORAES, A. Aplicando a antropometria ao design de produto - estações de trabalho e mobiliários. Revista Estudos em Design, PUC, v.8, n.3, p. 27 - 51, Rio de Janeiro, 2000.

RYBEZYNSKI, Witold. Casa: pequena história de uma ideia. Rio de Janeiro: Record, 1999.

SUDSILOWSKY, Sérgio. Entre a razão e o senso comum: uma análise morfológica da configuração do espaço na arquitetura moderna. XXV Congresso Brasileiro de Ciências e Comunicação. Salvador, 2002. Disponível em:

<http://www.portcom.intercom.org.br/pdfs/147541439137649675483329051433134371910.p df>. Acesso em: 22 abr. 2015.

VILLAROUCO, Vilma; ANDRETO, Luiz F. M.. Avaliando desempenho de espaços de trabalho sob o enfoque da ergonomia do ambiente construído. Prod., São Paulo, v. 18, n. 3, p. 523-539, Dez. 2008. Disponível em:< http://www.scielo.br/scielo.php?pid=S0103$65132008000300009 \&$ script=sci_arttext>. Acesso em: 25 out. 2015

WALDOW, Vera Regina. Cuidar: expressão humanizadora da enfermagem. $2^{\underline{a}}$ edição. Petrópolis, RJ: Vozes, 2007. 